\title{
A Redescription of ZaVrelia simantoneoa (SASa, Suzuki and Sakai, 1998) COMB. NOV.
}

\author{
Tadashi Kobayashi \\ 3-2-4-303 Mita, Tama Ward, Kawasaki City, Kanagawa, Japan. E-mail: tadkoba@,k.email.ne.jp
}

\begin{abstract}
Examination of the holotype of Micropsectra simantoneoa Sasa, Suzuki and Sakai, 1998 revealed that the species should be transferred to the genus Zavrelia. The male adult has hairy eyes, antennae with 10 flagellomeres, a costa ending proximal to the tip of $\mathrm{M}_{3+4}$, and a short and flattened superior volsella. This is the second Zavrelia species from Japan, and the $11^{\text {th }}$ in the world.
\end{abstract}

\section{Introduction}

The genus Zavrelia was established by Kieffer, Thienemann and Bause in Bause (1913) for Z. pentatoma Kieffer and Bause in Bause, 1913 (Ashe and Cranston 1990, Ekrem and Stur 2009). The genus is placed in subtribe Zavreliina within tribe Tanytarsini, subfamily Chironomnae, and was recently reviewed by Ekrem and Stur (2009). Ten Zavrelia species are known so far: Z. aristata Ekrem and Stur, 2009, Z. bragremia Guo and Wang, 2007; Z. casasi Ekrem and Stur, 2009; Z. clinovolsella Guo and Wang, 2004; Z. elenae Zorina, 2008; Z. hudsoni Ekrem and Stur, 2009; Z. pentatoma Kieffer and Bausa in Bause, 1913; Z. pseudopentatoma Zorina, 2008; Z. sinica Ekrem and Stur, 2009, and Z. tusimatijea (Sasa and Suzuki, 1999).

Only five records of genus Zavrelia have previously been known from Japan, including Z. tusimatijea (Sasa and Suzuki 1999) and Z. kibunensis (Tokunaga 1938), which was transferred from the genera Tanytarsus vand der Wulp, 1874 and Neozavrelia Goetghebuer, 1941 by Ekrem respectively (2002, 2006). The remaining three belong to unnamed Zavrelia species: a larva from Kokubunji Cliff Springs, Tokyo, by Ohno et al. (1999); an adult female from the Shinano River, Ueda, Nagano recorded by Hirabayashi et al. (2001); and a larva from the Takahari River, Okayama by Kitagawa (2003).

During reexamination of Micropsectra type specimens described by Sasa, Micropsectra simantoneoa Sasa, Suzuki and Sakai, 1998 was found also to fit the diagnosis of Zavrelia.

\section{Zavrelia simantoneoa (Sasa, Suzuki and Sakai, 1998) comb. nov.}

Micropsectra simantoneoa Sasa, Suzuki and Sakai, 1998: 62 (adult male, fig. 15).

Holotype: NSMT-I-Dip.5206 (SC.358-62), adult male labelled as "Micropsectra simantoneoa". Collecting data: Shimanto River, Nakamura Town, Shimanto, Kochi; 26.IV.1998, light trap, H. Suzuki.

\section{Diagnosis}

Zavrelia simantoneoa (Sasa, Suzuki and Sakai, 1998) can be separated from the other described Zavrelia species by the following combination of characters. Superior volsella broad, almost parallel sided and with rounded apex; lamellae of median volsella simple, directed medially; anal point without spinules between crests.

\section{Redescription}

Total length $1.88 \mathrm{~mm}$, wing length $1.08 \mathrm{~mm}$ (cit. Sasa, Suzuki and Sakai 1998, 62.). Ground colour of scutum, and scutellum yellow; vittae and postnotum brown, abdomen yellowish brown, distal half of femora brownish yellow, other leg portions yellow (ibid.).

Head: Frontal tubercle absent. Superorbitals 3:3, eye (Fig. 1) hairy, without dorsomedial extension.

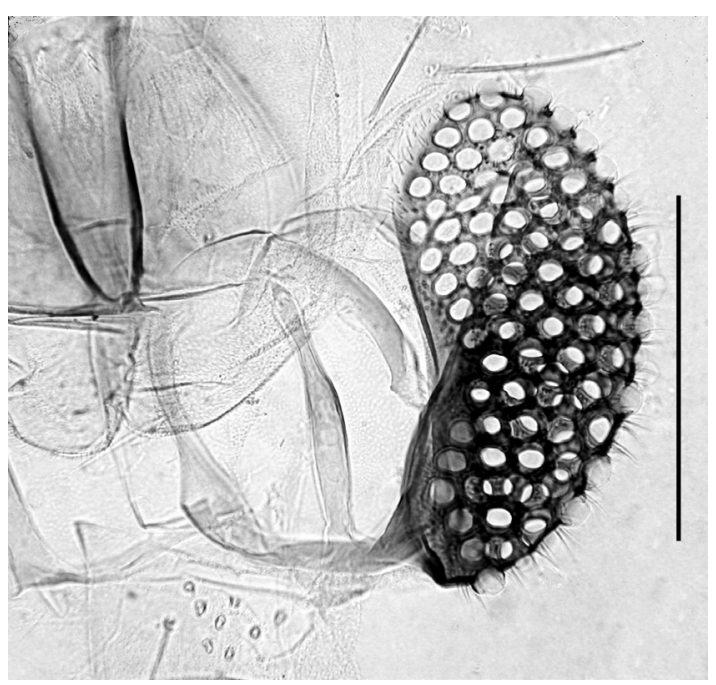

Figure 1. Eye, scale bar $=100 \mu \mathrm{m}$. 

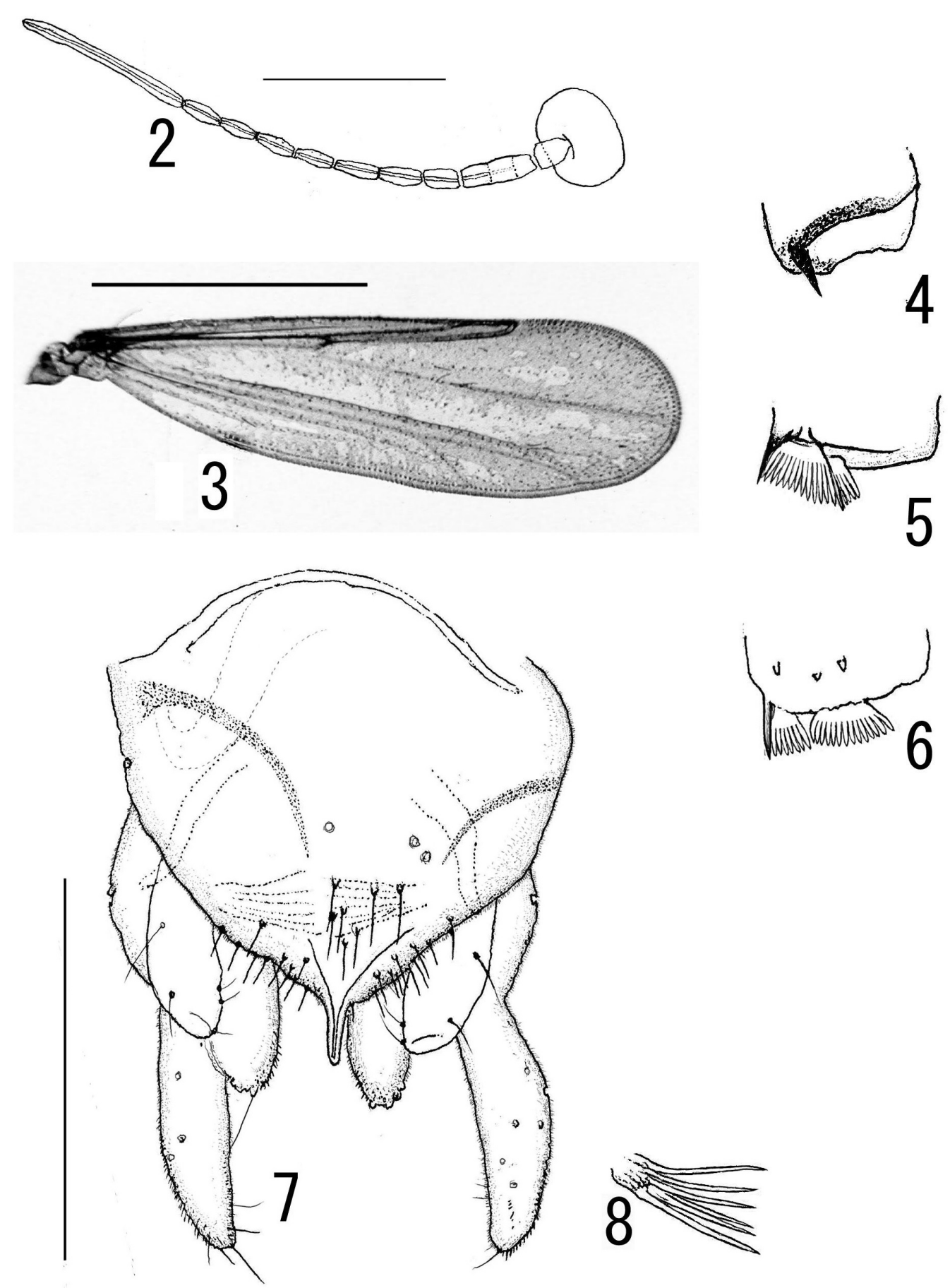

Figures 2-8. 2, antenna, scale bar $=200 \mu \mathrm{m} ; 3$, wing, scale bar $=1,00 \mathrm{~mm}$; 4 , apex of fore tibia, scale bar $=50 \mu \mathrm{m} ; 5$, apex of mid tibia, scale bar $=50 \mu \mathrm{m} ; 6$, apex of hind tibia, scale bar $=50 \mu \mathrm{m} ; 7$, hypopygium, scale bar $=100 \mu \mathrm{m} ; 8$, median volsella.

Antenna (Fig. 2) $578 \mu \mathrm{m}$ long, with 10 flagellomeres, $2^{\text {nd }}$ flagellomere long $(75 \mu \mathrm{m})$ with 2 discernible vestigial joint (incomplete fusion), $3^{\text {rd }}$ to $9^{\text {th }}$ flagellomeres about $40 \mu \mathrm{m}$ long each one; groove beginning at distal part of $2^{\text {nd }}$ flagellomere, AR 0.45 . Clypeals 9. Palp long, palpomere lengths in $\mu \mathrm{m} \mathrm{I}$ 25, II 28, III 90, IV 93, V 129, palpomere III with sensilla chaetica near apex; tentorium $42 \mu \mathrm{m}$ long and $5 \mu \mathrm{m}$ wide at most. Thorax chaetotaxy: Aps absent. Ac 11 biserial, Dc uniserial 9:9, Pa 1:1, Sct 2. Wing (Fig. 3): Wedge-shaped, widest near apex; squama bare, anal lobe weak, with macrotrichia more densely in distal half. Membrane with macrotrichia in all cells except anterior to vein $\mathrm{M}$; all veins with macrotrichia except $\mathrm{M}$ and $\mathrm{Sc}$; costal extension absent. $\mathrm{R}_{4+5}$ ending far proximal to 
Table 1. Lengths (in $\mu \mathrm{m}$ ) and proportions of legs.

\begin{tabular}{lcccccccc}
\hline & $\mathrm{fe}$ & $\mathrm{ti}$ & $\mathrm{ta}_{1}$ & $\mathrm{ta}_{2}$ & $\mathrm{ta}_{3}$ & $\mathrm{ta}_{4}$ & $\mathrm{ta}_{5}$ & $\mathrm{LR}$ \\
\hline $\mathrm{p}_{1}$ & 410 & 240 & 470 & 225 & 140 & 100 & 60 & 1.96 \\
$\mathrm{p}_{2}$ & 460 & 350 & 215 & 105 & 80 & 60 & 50 & 0.61 \\
$\mathrm{p}_{3}$ & 560 & - & 290 & 150 & & - & - & - \\
\hline
\end{tabular}

apex of $\mathrm{M}_{3+4} \cdot \mathrm{R}_{2+3}$ obscure, closely along $\mathrm{R}_{4+5} . \mathrm{FCu}$ much distal to $\mathrm{RM}, \mathrm{VR} 1.55, \mathrm{Cu}_{2}$ straight and short $(150 \mu \mathrm{m})$. Legs (Table 1, Figs 4-6): Apex of fore tibia with short spur $(10 \mu \mathrm{m}$ long), tibiae of mid and hind legs with two combs and one short spur at least, sensilla chaetica apparently absent from all tarsomeres. LR1 1.96, LR2 0.61, LR3 unmeasurable (' 0.75 ' in the original description); pulvilli absent. Hypopygium (Fig. 7): Laterosternite IX with setae, anal tergite bands separated, 7 median tergite setae placed mainly in dorsomedial area basally of anal point.

Anal point $15 \mu \mathrm{m}$ long, almost parallel-sided, without spinulae between crests; widest at base and tapering towards round apex, with narrow anal crests; 6 basal and 6 lateral setae. Superior volsella with broad base, setiger rounded apically, with 3 median and 2 lateral setae, without basomedial seta. Median volsella (Fig. 8) $8 \mu \mathrm{m}$ long, medially directed with 6-7 simple, $22 \mu \mathrm{m}$ long lamellae. Inferior volsella covered with microtrichiae, with several distal long setae. Gonostylus simple, narrow, inner margin slightly concave.

\section{Discussion}

In the 'Remarks', Sasa et al. (1998) state "this specimen is provisionally classified into the genus Micropsectra Kieffer, 1915", and "it is quite unusual as a member of the Micropsectra-Paratanytarsus group". As the holotype has hairy eyes, broad and flattened superior volsella, and short, medially directed median volsella with simple lamellae, it certainly does not belong to the genus Micropsectra but to Zavrelia.

In the key to adult males of Zavrelia by Ekrem and Stur (2009), Z. simantoneoa cannot advance beyond couplet 3 . This couplet separates species with "Setiger of superior volsella with obvious constriction in apical 1/3; anal point bare or with microtrichia in between crests" from species with "Setiger of superior volsella without constriction in apical 1/3; anal point with numerous microtrichia or small spinules". The present specimen has a setiger of superior volsella without constriction in apical $1 / 3$ and a bare anal point in between crests. Thus, it does not fit any other presently keyed $Z a-$ vrelia species and is different from all previously described species.

\section{Acknowledgements}

The author should express his acknowledgements to Dr. Torbjørn Ekrem of NTNU University Museum, Trondheim, Norway for encouragement to submit this manuscript and kind proofreading for the Chironomus Newsletter, and also to Dr. Akihiko Shinohara of National Museum of Nature and Science, Tsukuba, Japan for loan of the type specimen of Sasa collection.

\section{References}

Ashe, P.D. and Cranston P.S. 1990. Family Chironomidae. In: (Eds.: Soos, A. and L. Papp) Catalogue of Palaerctic Diptera, PsychodidaeChironomidae. Vol. 2. - Akademiai Kiado Budapest, 113-355.

Bause, E. 1913. Die Metamorphose der Gattung Tanytarsus und einiger verwandter Tendipedidenarten. Ein Beitrag zur Systematik der Tendipediden. - Archiv für Hydrobiologie Supplement 2: 1-126, Taf. I-XVI.

Ekrem, T. 2002. A review of selected South- and East Asian Tanytarsus vd. Wulp (Diptera: Chironomidae). - Hydrobiologia 474: 1-39.

Ekrem, T. 2006. A redescription of Neozavrelia cuneipennis (Edwards) comb. nov. with a checklist of Neozavrelia species of the world (Diptera: Chironomidae). - Zootaxa: 1153: 1-16.

Ekrem, T. and Stur, E. 2009. A review of the genus Zavrelia (Diptera: Chironomidae). - European Journal of Entomology 106: 119-144.

Hirabayashi, K., Nishio, N. and Yamamoto, M. 2001. Research on the distribution and ecology of chironomid adults in the Inland Climate Area - Chironomid adults in summer and autumn seasons, in Ueda Basin. - Medical Entomology and Zoology 52(2): 87-96. (In Japanese).

Kitagawa, N. 2003. Taxonomy of chironomid larvae (5), Freshwater Organisms 88, pp.155. (In Japanese).

Ohno, M., Tsukui, K., Wanami, K., Furusawa, K., Kazama, M. and Imamoto, N. 1999. A survey of aquatic life in Kokubunji Cliff Springs. $A n-$ nual Report of Tokyo Metropolitan Institute for Environmental Science Research 1999: 100106. (In Japanese). 
Sasa, M., Suzuki, H. and Sakai, T. 1998. Studies on the Chironomid Midges Collected on the Shore of Shimanto River in April, 1998. Part I. Description of Species of the Subfamily Chironominae. - Tropical Medicine 40(2): 47-89.

Article submitted 25. September 2014, accepted 16. October 2014, published 22. December 2014. 